\title{
Analyses of the advantages and risk aversion of chain management
}

\author{
LiuNa
}

DaLian Vocational Technical College 116000

Keywords: chain; advantages; risk aversion

\begin{abstract}
With the rapid progress of economic and social development, the chain management as a typical representative of business, has become the mainstream of society with a strong flow of force now, although there are some advantages of the chain, but the chain of the market also has a risk, in order to address the risks, the chain must do the publicity and training, do market research and analyses, to deal with the violations in a timely manner, thus boosting economic development, make good use of the benefits of chain management, further improve risk avoid.

In the current commercial society,the chain is more prominent, our government puts forward the implementation of circulation modernization's focus is the chain operation,in our country, especially in recent years, the rapid development of chain management, and even less than some developed country, but at this stage the chain still exists some problems, businesses and rules on the use of chain management master is not enough, there are some risks, so we need to analyze the merits of the chain, to avoid market risks, optimization allocation of resources, enhance the competitiveness of enterprises.
\end{abstract}

\section{The advantages of chain management}

1.1 Preferred of young people. Now, most college students have chosen to start their own businesses after graduation, they were young and knowledge, and carried the dream,chain management is the first choice of entrepreneurship for their.Many areas are involved, for example, catering and cake as well as clothing, etc., have become a hot industry. Many young people through this way to get rich, a large part of this part of the young people just is out of college students, they are enthusiastic, positive, cherished dreams, high-spirited, high morale. GuiZhou news reported on a college student after graduation to give up high-paying jobs, came back to conduct their own businesses, and in a few short years, opened a chain, you can see that the chain in the next generation of young people is very popular, this is commendable. Society is evolving, that it needs a group of young people to promote the development of society, and they prefer to the chain, which will be a big advantage in the China, in the near future chain will occupy the Chinese market,to be a commercial leader.

1.2 The advantage of brand effect. With the reform and opening up, improved people's living standards, more and more people pay attention to the quality of life, popular terms is increasingly focusing on brand when buying a product will be given priority. Doing business in a product, there is a strict quality control, whether it is inside the packaging or packaged goods often has strict audit, maintenance of a unified service quality and management level, and further establish a distinctive unique corporate image, analogy, now catering prevailing society, most people would choose to eat when traveling some of KFC, MCD's and other fast food restaurants, but not casually choose a restaurant, the well-known supermarket will be selected, for example, US Wal-Mart, Carrefour of France as well as Germany's Metro and other retailers. Because the chain makes them known for these brands supermarkets in China, has become well-known brands that are as small as a commodity, to a large household appliances, all reflect the benefits of the chain, which by its own cross-regional the rapid expansion of exaggerated sales, higher profit, also through strong regional open itself its own brand, Wal-Mart now has more than 1000 own brand in China, Carrefour has more than 2,000 brands, a lot of big brands through the chain improves the impact strength, for example, in France, a reference to Chanel, the first reaction of consumers is a good quality.

1.3Expand the size advantage. Chain management is a new wave of forces which is raging fire, 
economies of scale more and more is paid attention,we give a simple example,to compare, ZhouHeiYa chains, I believe we have eaten the ZhouHeiYa, this is so little in the beginning, now, ZhouHeiYa has been throughout the major cities, whether through a network or a variety store, ZhouHeiYa brand has clearly done very loud, of course, Chinese GuoMei,due to the acquisition of Paradise door head shop 202, has expanded rapidly in the last century as well as well-known all over ShangHai LianHua firm streets, LianHua firm is a chain of early industry leader, Vanguard and SuGuo supermarket chain industry is an early start in business, the chain is due to the continuous expansion of economies of scale drive,regular chain, franchise chain and freedom in favor of capital accumulation, can also increase the number of stores by way of freedom to join, you do not need to invest in persons case. The larger the size of the chain, the more recognized by people, the chain has become the world among the best, most competitive retail business.

1.4Price control advantage. On the one hand,the chain is popular because of the low cost chain management,higher costs accounted for advantage,according to the conventional, the purchase price of goods is usually very low, but also buy the lower the price the more so since it costs itself is low, it corresponds to the goods sold price is low, so loved by the masses, consumers get the benefits, buy cheap goods, and thus the gospel chain operation will come, so just let chains With fertile soil management. The more appropriate cost control, the more sought after people receive, which is rather questionable, usually in a short period of time, the performance brand will be very obvious, many businesses through price competition to win consumers recognition and favor of consumers in the process of consumption will be a conscious choice of their own trust business, is the so-called chain predecessors trees descendants cool, play a good role behind the front to join to join, it play a good influence on the chain, so that complement each other.

1.5To expand the market. Rapid economic development and social progress in, the chain also continues to improve, the market share is growing,not just the chain,the commercial nature of catering clothing is expanding, the only constant expansion of continuous improvement can bring efficiency and profits. Today's society requires constant innovation,we live in this network and information technology developed society, you want a place in the market will continue to expand, market share. This business is not easy, by the chain business model to expand the market and get the majority of consumers can not do without their own efforts,only in the market to play its effectiveness, the chain can be a steady stream of development down.

\section{The risk of chain management}

Everything has two sides, the chain has many advantages now, it must also exist many potential risks, we should correctly understand these risks, identify the location of these problems and resolve these issues in order to be good for our business.

2.1The risk of lack of experience. We mentioned earlier the chain popular in college graduates, however, not all young people will succeed, most of them are just out of college students do not have a rich social experience,lack of experience in business management, failing running out of patience, unable to withstand the blow and setback, poor psychological quality in management and business decisions astray to bear in, low self-esteem, which can affect their development. As a new era of us, no matter what kind of business should possess the necessary skills and quality of the industry, everything is hard in the beginning to understand the truth, things are not all smooth sailing, in the face of important decisions, perhaps because of poor decisions bring business risk, this risk is the risk of the operator to bring the consequences of this risk is sometimes caused is beyond measure and even lead to bankruptcy.

2.2 The risk of the social environment. The economy is subjected to certain environmental and social impact of the geographical environment, like the impact of the financial crisis is a major, unpredictable market economy, consumer demands are endless, chain management to adapt to the changing social environment, nothing is immutable, that is, the chai $\mathrm{n}$ must change with changes in the social environment, economic development in different periods, and give the operator a high degree of attention, since the reform and opening up, the market has become more open, the face of fierce competition in the market, the operator should always keep a clear head, the face of volatile 
markets must be caution when social-economic downturn, liquidity is often not strong, which hindered economic development, so it is with the social environment to risk.

2.3 The risk of liquidity. In the enterprise management may be because the operators income or sit in cash,illegal accounts or embezzlement without permission, resulting in the capital turnover don't open, so enterprises should establish a sound system of financial responsibility, within the allowable range and spend cash income or sit, or because managers mismanagement, resulting in a shortage of property losses incurred, the original insufficient capital investment, the management of all kinds of loopholes will cause all sorts of risk capital for each chain are limited, because the work is essential to good cash flow of. Once the cash flow, however, the venture also suffered immeasurable.

2.4 The risk of no perfect system. Despite the rapid development of Chinese chain experience, but compared to developed countries, China had experienced chain system imperfect, the need for further improvement and progress, at this stage of the chain is not standardized, there are still many vulnerabilities plot small into many easily lead to operational risks. in addition, the chain is also affected by the legal system, the impact of tax payment, local protection and other aspects, many policies are persuasive rather than conclusive, there is no strong binding. Thus, the imperfect system of risk managers also need attention.

\section{To avoid the risk of chain}

3.1The right to judge market environment.Some operators do not have a correct understanding of their own business situation, blindly follow the crowd, chasing blindly forward, ignoring its own operating system, the operator in the operation and management to correctly judge the market environment, according to its own situation from the practical to the mode of operation with the changes in the market environment changes, not static, observe changes of the market environment, lessons learned, from analysis to assess and improve the institutional system of enterprises, according to the professional judgment of the operator to analyze the market price fluctuations, improve the management and operation ability to make decisions, and constantly improve the system of rules, obtain profitability and solvency to detect changes in the market environment, the consolidation of chain management, improve the competitiveness of the chain and enhance their strength.

3.2 Carry out inspection and assessment. After risk management system be implemented, but also to be inspected and evaluated for a particular period of corporate financial statements and certain accounting period of supervision and inspection, access to relevant information, who is responsible who should responsible for the management of the existence of fraud, check out the problem to be in time for special projects and transactions to identify matters clear, special items special treatment, and to make timely evaluation, supervision and inspection of the results of its evaluation, the existence of improper trading, the identification of each transaction and spending issues and for a subsequent period of major uncertainty matters specific supplement, in order to avoid errors and other issues, resulting in unnecessary losses. Therefore, to do inspection and evaluation work is also a vital role in the chain of management.

3.3Establish and improve the economic responsibility system. Only a company to establish and improve economic accountability system will bring economic benefits, the same, the chain is, the situation needs to be timely cash income or sit, the scope of cash expenditures must be strictly enforced in accordance with the rules and regulations, for example, travel costs of mission personnel, salary bonuses. Unless required by law case, the operator may not income or sit in cash, in addition to proprietary matters, funding will be through the base card for deposit accounts can not be set up illegal accounts, as well as to achieve separation of duties, so that inside each other to contain, for example, the cashier can not also responsible for the general ledger and journal management, in order to take preventive measures, to establish and improve the responsibility system is conducive to economic operators proper management companies and make the right business decisions, maintain financial law, improve economic efficiency, improve business development, promote enterprise economic development. Good economic responsibility system is a 
manifestation of the spirit of the chain.

3.4 Establishment of sound competition and incentive system. Establish and improve the competition and incentive system, employees have the opportunity to display their talent and help employees achieve the goal, a business needs good employees in order to promote a positive nature, to fully exploit its potential, and the operators have to take to stimulate employee made the enthusiasm, the enthusiasm of the staff full drive up, will play its head, so the operator to set up the bonus system, for example, attendance bonus, year-end bonus awards, etc., so that employees motivated, full and comprehensive evaluation of the actual situation of employees, of course, errors caused by employees loss is to punish, the operator penalties and rewards to do in order to improve the enterprise system, for some couples to be more cultivated, develop their potential, as well as to stimulate the sense of competition staff, the staff always full of a sense of urgency, establish and improve the competitive and incentive systems in an enterprise development is particularly important, especially in chain management in the mall has always been survival of the fittest, not those out. Establish and improve the competition and incentive systems can help enterprises to continuously improve themselves, identify vulnerabilities, in time, will help enterprises continue to move forward, economies of scale, thus boosting economic growth.

\section{Conclusion}

Society is progressive, science and technology is evolving,the chain has become a mainstream business,the chain continues to progress at the same time also need to constantly improve, both operators and consumers, in today's society is very focus on the chain of this model,since the reform and opening up, the rapid social and economic development, the chain began to emerge in recent years, and the results amazing, but with it comes the risk can not be ignored, the correct response would be appropriate very effective to avoid the risk, therefore, the operator correctly advantages and risks and avoidance measures for the management of treatment help to promote and optimize the economic structure and improving economic efficiency.

\section{References}

[1] Zhao Yongjian, et al. Laboratory construction and management of the laboratory of Nihon University [J]. Laboratory technology and management, 2002, 19 (6): 1-6.

[2] Fang Hai. Construction and practice of comprehensive quality management system for undergraduate teaching in higher education [J]. China higher education, 2007, (5): 21-22..

[3] Chen Hui. Construction and exploration of undergraduate teaching quality monitoring system in research universities [J]. Higher education of science, 2006, (1): 7-10.

[4] Yu Haizhen. Experimental teaching quality monitoring and management organization analysis [J]. Experimental science and technology, 2008, 6 (4): 86-88.

[5] Shi Shengqi. On the reform of experiment teaching in twenty-first Century [J].Laboratory research and exploration, 1999(2): 6-8. 